\title{
Responding to Climate Change as a Transformative Stressor through Metro- Regional Planning
}

\author{
Tony Matthews*
}

\author{
Urban Research Program (URP), Griffith Climate Change Response Program \\ (GCCRP), Southeast Queensland Climate Adaptation Research Initiative (SEQ-CARI), \\ Griffith University, 170 Kessels Road, Nathan, Queensland 4111, Australia.
}

\begin{abstract}
This paper characterises climate change as a 'transformative stressor.' It argues that institutional change will become increasingly necessary as institutions seek to reorientate governance frameworks to better manage the transformative stresses created by climate change in urban environments. Urban and metropolitan planning regimes are identified as central institutions in addressing this challenge. The operationalisation of climate adaptation is identified as a central tenet of a comprehensive urban response to the transformative stresses that climate change is predicted to create. Operationalisation refers to climate adaptation becoming incorporated, codified and implemented as a central tenet of urban planning governance. This paper has three purposes. First, it examines conceptual perspectives on the role of transformative stressors in compelling institutional change. Second, it establishes a conceptual approach that characterises climate change as a transformative stressor requiring institutional change within planning frameworks. Third, it reports emergent results and analysis from an empirical inquiry which examines how the metro-regional planning regime of Southeast Queensland (SEQ) has responded to climate change as a transformative stressor via institutional change and the operationalisation of climate adaptation.
\end{abstract}

Keywords: transformative stressors; climate change; institutional change; metro-regional planning

\section{Introduction}

Climate change represents a real and immediate threat and will create increasing levels of stress in urbanised areas over the course of this century (Garnaut 2008, IPCC 2007). Extensive efforts towards mitigation remain a critical response, but climate change adaptation must now also be understood as an urban imperative (IPCC 2007, Stern 2006, Wilson and Piper 2010). Efforts to manage climate change impacts in urban areas will require institutional change as institutions charged with the management of urban environments reorientate in order to deliver new rules of governance, which are better designed to respond to the climate adaptation imperative. Climate adaptation must become operationalised as a central tenet of urban and metropolitan governance. Operationalisation in this instance refers to climate adaptation becoming incorporated, codified and implemented as central tenet of urban governance. Planning regimes are key urban institutions and play an important role in coordinating, structuring and

\footnotetext{
*Email: t.matthews@griffith.edu.au
} 
managing urban and metropolitan areas. Accordingly, the operationalisation of climate adaptation is represents a key planning challenge.

This paper has three purposes. First, it examines social scientific perspectives on institutional change processes and how change is prompted by trigger events and their associated stresses. It argues that existing scholarly understandings of institutional change underestimate the fact that particular stressors have the capacity to compel institutional change, irrespective of the influence of institutional actors and institutional capacity. A new typology of stressors is presented, referred to as 'transformative stressors.' It is argued that when transformative stressors occur, they can compel institutional change by virtue of their acute severity. In this regard, the transformative stressors typology offers a new conceptual model for understanding institutional change in specific contexts. Second, this paper establishes a conceptual perspective that understands climate change as a transformative stressor requiring institutional change within the planning frameworks governing cities and metropolitan regions. An examination of the role of planning regimes in responding to climate change as a transformative stressor through climate adaptation in urban environments follows. Planning regimes are characterised as social institutions that seek to direct development in specific ways through the imposition of rules of governance which are expressed through planning policies and regulations. Third, it reports early findings from an on-going enquiry examining how the metro-regional planning regime of Southeast Queensland (SEQ), Australia, has responded to climate change as a transformative stressor in a metropolitan context. Specifically, it investigates how the SEQ metro-regional planning regime responded to climate change as a transformative stressor in period from 2004 to 2010 through the operationalisation of climate adaptation as a central tenet of planning governance.

\section{How transformative stressors can compel institutional change}

The role of institutions in guiding and managing social engagement has prompted a great deal of social scientific inquiry. Scholarship demonstrates a wide spectrum of thinking and critique focused on definitively characterising institutions as social scientific objects. Institutions are broadly understood as providing the 'generalised regulatory framework for socially acceptable behaviour' (Connor and Dovers 2002, p. 7). In other words, they are social entities that structure and coordinate social interaction across a variety of settings (Alexander 2005, Connor and Dovers 2004, March and Olsen 1989, North 1990, Peters 2005). Institutions shape human behaviour and social interaction by creating and imposing rules of governance, which may be may be formal or informal or a combination of both (Connor and Dovers 2002, 2004, North 1990, Young 2010). Formal rules include constitutions, law, rules and regulatory provisions; informal rules include social conventions and commonly recognised behavioural norms. In addition to imposing rules of governance, institutions have enforcement functions designed to ensure compliance with their established rules (March and Olsen 1989, North 1990, Young 2010). Institutions therefore have two key and inter-related functions: the imposition of rules and the pursuit of compliance. Institutional rules of governance can be expressed as a single rule or as a hierarchy, where compliance is required at each stage of social engagement in order to advance to 
subsequent stages. Institutions exist in many forms and co-ordinate social interaction and behaviour in a multiplicity of settings. Their functions can range from the relatively straight-forward, such as ensuring that drivers are licensed and tested, to more complex pursuits, such as guiding and managing urban and metropolitan environments through planning governance.

An important characteristic of institutions is their capacity for change. Institutional change happens when an institution amends or reorientates its rule set in order to deliver improved social outcomes by directing social behaviour in new or different ways (Alexander 2005, Kingston and Caballero 2009). An institution can undergo change when faced with particular events or phenomena that are not easily managed through existing rules of governance. When this happens, the institution is faced with two choices. In the first instance, the institution can conceptualise the nature, impact and extent of the change dynamic and respond to it through a process of change and the operationalisation of new or improved rules. In the second instance, the change dynamic can be resisted or ignored. A consistent failure to respond can lead to the institution becoming irrelevant or unfit for purpose (Cortell and Peterson 1999, Young 2010). Upon reaching this point, the institution is likely to be dissolved or replaced. The capacity of any institution to undergo a change process is conditioned by the nature and character of both the institution and the change dynamic, along with the influence of internal and external institutional actors (Cortell and Peterson 1999, Hogan 2006, Young 1999, 2002). Institutional capacity to react to a change dynamic varies considerably. Some institutions change quickly and freely, while others resist change or change slowly. In the latter case, institutions confronted with demanding change dynamics can be resistant due to institutional arthritis, a condition where institutions become entrenched and unable to adapt to new imperatives (Olsen 1982, Young 2010). This is also referred to as institutional inertia (Dovers and Hezri 2010). I submit that the term 'institutional sclerosis' is equally apt in describing institutional resistance to change dynamics.

Institutional change is often prompted by an external crisis or series of crisis moments (Cortell and Peterson 1999, Hogan 2006, Schmidt 2010, Young 1999, 2002, 2010). These function as triggers by creating and escalating social stresses, which consequently prompt institutional change as affected institutions attempt to manage the impacts of the change dynamic and associate stresses. Responses are implemented through the development of new or amended rules of governance. Examples of crisis events might include significant demographic change, a resource shock, a public health emergency or an unanticipated fall or rise in economic activity. Institutions that respond adequately through change processes leading to new rules of governance can maintain their relevance, whilst those unwilling or unable to change face becoming irrelevant (Olsen 1982, Young $1999,2010)$. Institutional change is broadly divided into two categories: episodic change, which is rapid and dramatic and incremental change, which is slow and gradual (Krasner 1984, North 1990,1993). In certain cases, stresses may initially be minor, prompting incremental change, before increasing in scope and impact and ultimately converting incremental change into episodic change (Young 2010).

Trigger events and their associated stresses are not always sufficient to compel institutional change. Whilst trigger events do create social stress, 
institutional responses to change dynamics are also strongly conditioned by two other factors. These are change-orientated preferences and institutional capacity (Cortell and Peterson 1999, Hajer 1993, 1995, March and Olsen 1989, North 1990, Young 2010). Change-orientated preferences refer to the manner in which the reactions of institutional actors can shape whether institutional change follows a trigger event. Institutional actors may be internal or external institutional actors, including appointed or elected state and policy officials, external consultants and public stakeholders. Responses to a change imperative may be problematic in situations where actors are presented with change dynamics that require institutions to confront problems that are substantively different in scale and character to those previously encountered (David 1985, Low and Astle 2009, Moser and Ekstrom 2010). Difficulties can arise as actors fail to understand or ignore the gravity of a change dynamic and consequently hinder or block institutional change processes. Institutional capacity refers to the manner in which an actor's ability to take advantage of an opportunity for change depends on their institutional position. Accordingly, some actors may recognise a crisis event and associated window of opportunity and may seek to respond through institutional change, only to be over-ruled by the preferences of other actors. In such cases, institutional change is unlikely. Whether this is an appropriate and suitable outcome depends on the nature and severity of the particular crisis event, along with the magnitude of the social stresses it brings.

Institutional actors exert strong influence on institutional decision making, especially when related to institutional change processes (Hajer 1993, 1995, March and Olsen 1989, North 1990, Young 2010). The ways actors respond to broader changes imperatives in their domestic and international environments heavily characterises the nature of institutional change (Cortell and Peterson 1999). As McFaul (1995, p. 216) succinctly argues, institutions 'do not change of their own accord; they are changed.' Actor's perspectives can potentially be shaped by a multiplicity of factors, including but not limited to, the influence of lobby groups (Liebcap 1989), levels of understanding relating to new or emerging social phenomena (Fünfgeld 2010, Moser and Ekstrom 2010), collective bargaining (Alston 1996) and political objectives (Ostrom 2005). Storylines may also be highly influential in institutional contexts (Hajer 1993, 1995). Hajer characterises storylines as 'narratives on social reality through which elements from many different domains are combined and that provide actors with a set of symbolic references that suggest a common understanding' (1995, p. 62). Storylines can cluster knowledge, position social actors and lead to the formation of discourse coalitions, which are a set of beliefs or perspectives subscribed to by actors who collectively adhere to particular storylines. Hajer (1993, 1995) argues that dominant storylines shared by institutional actors have significant capacity to shape decision-making around institutional change. Path dependency may also influence institutional change. This occurs when institutions resist a process of institutional change because of an embedded focus on a particular set of issues (Cortell and Peterson 1999, David 1985, Low and Astle 2009). In cases of path dependency, institutions and their actors become used to dealing with particular perspectives and resist anything that might require them to engage with new or different thinking. This creates a form of myopia, which can undermine 
institutional capacity for confronting new or emerging challenges. Path dependency often leads to situations where "institutions that have grown up around one sort of problem may be unable to respond adequately when confronted by a quite different sort of problem" (Low and Astle 2009, p. 48). In other words, a change imperative may be valid and real, yet be resisted because it requires institutional engagement with a set of issues outside of the familiar and institutionally accepted.

I argue that whilst these scholarly perspectives on institutional change correctly identify crisis events as key triggers for prompting institutional change, they are undermined by the contention that institutional actors matter more in directing institutional change than the change imperative and its associated social stresses. I submit that a new conceptualisation of institutional change is needed to account for this deficiency in scholarship. This is based on my proposition that certain stressors possess sufficient capacity to compel institutional change, due to the severity of their social consequences. I argue that in certain circumstances, the impacts of particular stressors can be severe enough to compel institutional change, regardless of change-orientated preferences or institutional capacity. In such cases, I contend that embedded path dependencies and dominant institutional storylines can also be swept aside by the severity of the change imperative and its associated social stresses. I refer to these as transformative stressors. Though uncommon, I submit that a limited number of transformative stressors currently exist and their impacts are already evident and leading to escalating social stresses. I contend that when faced with transformative stressors, institutions will be compelled to either change or become irrelevant and that actors and their personal preferences will assume less importance when institutions are faced with certain serious, pervasive and cumulative social stresses. In short, when they occur, transformative stressors possess the capacity to make institutional change an institutional and social imperative.

I characterise a transformative stressor as a chronic large-scale phenomenon which triggers a process of institutional change whereby institutions seek to reorientate their activities in order to better manage the social, economic and environmental impacts created by the transformative dynamic. As distinct from other social scientific conceptualisations of institutional change, the transformative stressors model is premised upon the argument that certain stressors have potential to become severe enough to compel institutional change, leading to large-scale structural modifications in an institutional context. In such cases, the transformative stressor and its impacts act as trigger events, which open windows of opportunity for institutional change. A transformative stressor, as distinct from other types of crisis event, demands institutional response because its wider social impact is so pervasive and severe. Institutions must either respond with new rules of governance or risk irrelevance when faced with a transformative stressor. Under this typology, change-orientated preferences or institutional capacity valid in shaping institutional responses through change processes, but the capacity of actors to block change is significantly diminished by the level of social stress created by the transformative stressor. This paper identifies climate change as a transformative stressor, though I argue that others. 
These include oil vulnerability, acute demographic change, water shortages and declining food security.

\section{CHARACTERISING CLIMATE CHANGE AS A TRANSFORMATIVE STRESSOR}

This paper identifies climate change as one example of a transformative stressor. It is fundamentally different from almost all other stress events faced by institutions. The phenomenon is large-scale, with the potential to create negative social impacts on national, regional and local levels. Climate science demonstrates clearly that climate change and its effects are likely to negatively affect and stress societies in many ways. Predicted impacts include physical harm to natural and man-made environments, economic costs, biodiversity losses and resource reductions (Garnaut 2008, IPCC 2007, Stern 2006). Institutional governance frameworks are and will be required to change and reorientate in order manage the severe environmental stresses wrought by climate change (Connor and Dovers 2002, Wilson and Piper, 2010). Many different types of institutions will be forced to react to increases in the frequency and severity of climate change impacts by conceptualising the character, impact and extent of the phenomenon as it applies to their sphere of governance. Negative social consequences will intensify and escalate in tandem with climate change impacts. Institutions will have no choice but to respond, or risk becoming obsolete. Institutional capacity and changeorientated preferences will remain important in conditioning responses to the change dynamic, though it is likely that institutions which display sclerosis will either need to undergo significant levels of reorientation or risk being replaced by alternative institutional arrangements better equipped to recognise and respond to climate change as a transformative stressor.

Urban governance frameworks are especially crucial in responding to climate change as a transformative stressor, especially as the majority of the world's population is now urbanised (UN 2009). The spatial character of urbanisation means that urban systems contribute significantly to climate change through form and structure, land-use patterns, energy demand and car dependence (Condon, Cavens and Miller 2008). The impact of climate change on many urban environments is likely to be severe (IPCC 2007, Gleeson 2008). I argue that climate change effects are already emerging as a cumulative change dynamic in an urban context and institutions charged with developing, implemented and maintaining urban governance frameworks will be compelled to respond to climate change as a transformative stressor. Institutional change will be necessary if social institutions are to adequately confront and manage the social stresses created by climate change impacts in urban environments. Efforts to advance climate change mitigation may still limit the severity and incidence of climate change effects, but are unlikely to eliminate all impacts (Garnaut 2008, Stern 2006). Consequently, I argue that a strong focus on operationalising climate change adaptation strategies through urban governance frameworks must become a central tenet of institutional responses to this transformative stressor in urban environments. A capacity for successful institutional change will therefore be vital in managing transformative stresses created by climate change. 


\section{Responding to a transformative stressor in urban environments through planning}

Institutions are fundamental to the successful management and co-ordination of urban environments (Fünfgeld 2010, Ruth and Coelho 2007). Institutions address their obligations through the imposition of governance frameworks designed to guide appropriate forms of social behaviour, as well as through the use of various mechanisms to ensure compliance. Planning regimes are fundamental institutions in this wider urban context. They function as social institutions that develop and implement governance frameworks to direct development activities within a set of rules and expectations across urban scales (Alexander 2005). Planning is characterised as a 'set of governance practices for developing and implementing strategies, plans, policies and projects, and for regulating the location, timing and form of development' (Healey et al 1999, p. 31). A key aim of planning governance in an urban context is therefore the regulation of strategic, spatial and land-use development and the implementation of regulatory frameworks and compliance mechanisms to ensure socially acceptable behaviour. Planning regimes also try to balance the particular needs of individuals and groups with broader social needs, including environmental management, the provision of infrastructure and preservation of amenity as part of this remit (Faludi 2000). Institutional change is required for planning regimes when existing rules of governance become inadequate in addressing changing circumstances created by social stresses (Alden, Albrechts and da Rosa Pires 2001, Alexander 2005, Forrester 1989). I argue that climate change, as a transformative stressor, will require planning regimes to undergo institutional change if they are to successfully contribute to wider efforts seeking to develop appropriate urban responses to the phenomenon. Specifically, I argue that planning regimes must undergo institutional change in order to deliver an improved operationalisation of climate adaptation as a means of managing wider social stresses created by climate change. The operationalisation of climate adaptation refers to adaptation becoming incorporated, codified and implemented as a central principal of planning governance.

Operationalising climate adaptation represents a new institutional challenge for planning regimes. Many scholars argue that the operationalisation of climate adaptation through planning governance represents one of the most urgent and serious tasks currently facing the planning profession (Gleeson 2008, Newman, Beatley and Boyer 2009, Smith et al 2010, Wilson and Piper 2010). I argue that adequately addressing this task will require institutional change. This need will become more acute as climate change impacts increase in severity and frequency in urban environments and the phenomenon begins to clearly manifest as a transformative stressor. Whilst efforts to respond to change dynamics may initially be resisted by institutional actors, I argue that climate change impacts, unlike many other stressors, will continue to escalate and will eventually reach a point where their wide-ranging social consequences and costs can no longer be ignored. Planning regimes can respond through institutional change, where the goal of the change process is to operationalise adaptation and in turn regulate the location, form and timing of development so that it is more resilient to climate change effects. In tandem with this, new regulations can be established to improve 
the resilience of existing urban environments, infrastructure and built capital. In both cases, delivering locally appropriate action is fundamental, as climate adaptation interventions work best when developed and implemented according to local conditions and needs (Matthews 2011a, Measham et al 2011, Wilson, 2006). Strategies that planning regimes may utilise in urban contexts include integrating adaptation strategies with specified implementation and monitoring strategies directly into development plans, codifying adaptive design standards for existing and new development, promoting retro-fitting, and promoting and harnessing community capacity (Matthews 2011b, Wilson and Piper 2010).

\section{Findings from Southeast Queensland (SEQ), Australia}

The remainder of this paper reports emergent findings from an on-going inquiry that examines how the metro-regional planning regime of Southeast Queensland (SEQ) has responded to climate change as a transformative stressor through institutional governance. The SEQ metro-regional planning regime is the principal institution with responsibility for developing and implementing governance frameworks to direct planning and development activities throughout the region. Responding to climate change as a transformative stressor is a necessary and important element of successful planning governance. Within this context, I identify the operationalisation of climate adaptation as a key institutional challenge. I argue that meeting this obligation requires the SEQ metro-regional planning regime to undergo a process of institutional change in order to deliver an improved operationalisation of climate adaptation through the enunciation of statutory planning policy and regulation. In doing so, the regime can improve its capacity for managing wider social stresses created by climate change impacts in SEQ. The nature and character of the SEQ metro-regional planning regime's responses to this challenge is assessed through a close examination of regional planning policies and regulations between 2004 and 2010, with a specific focus on the enunciation of policy and regulation related to managing climate change on a regional scale.

Southeast Queensland (SEQ) is a sub-tropical, heavily urbanised metropolitan region on Australia's east coast. It contains two of Australia's major cities, Brisbane and Gold Coast City, which are respectively third and sixth largest nationally. The SEQ metropolitan region forms a long coastal conurbation, running approximately 200 kilometres from Noosa in the north to Coolangatta in the south. Another major conurbation runs west from the coast, via Brisbane, to the city of Toowoomba. SEQ has a current population of approximately 2.7 million people and is the fastest growing metropolitan region in Australia. Regional population projections anticipate an increase to around 4.4 million people by 2031 (DIP 2009a, p. 8). Demand for housing, infrastructure, energy, employment and amenity is increasing steadily, leading to substantial development pressures in the region. These pressures are likely to be greatly exacerbated by predicted climate change impacts and so represent significant regional planning challenges (DIP 2009b).

The Intergovernmental Panel on Climate Change (IPCC) identifies SEQ as one of the six areas most vulnerable to climate change impacts in Australia (Hennessy et al 2007, p. 525). Predicted climate change impacts in SEQ during the 
current century include inland storm surges; reductions in water availability; increased coastal and inland inundation; sea level rises of up to $0.79 \mathrm{~m}$ over current levels and an increase in the number of days with temperatures in excess of $35^{\circ} \mathrm{C}$ (DIP 2009b, Hennessy et al 2007). The region is SEQ is already vulnerable to damaging weather events and natural hazards including bushfires, inland flooding and coastal storm surges. The metropolitan region of SEQ, already challenged by growing development pressures and existing natural hazards, now also faces nascent and potentially severe climate change stresses. The region's planning regime is a central institution in managing these pressures through metropolitan governance frameworks and associated policy and regulatory guidance. I argue that in this context, the operationalisation of climate adaptation represents a crucial institutional challenge for the SEQ metro-regional planning regime in managing climate change as a transformative stressor.

The analysis presented in this paper presents emergent findings on the nature and adequacy of the SEQ metro-regional planning regime's responses to climate change as a transformative stressor. It focuses on the period from 2004 to 2010. I argue that climate change became a transformative stressor for the SEQ planning regime from 2005 onwards. This date was established following an extensive and detailed examination of documents from 1990 to 2010. These included planning policy documents; government position papers; policy briefs and information statements; over 80 separate sets of minutes from official meetings held by various regional planning committees; and a detailed review of Queensland government parliamentary records covering 20 years. Data generated by this process was then used to identify and characterise major the institutional storylines (Hajer 1993, 1995) that influenced regional planning policy and regulation in respect of climate change. These storylines and the ways they shaped institutional thinking and action were subsequently tested through interview with past and present institutional actors in the SEQ metro-regional planning regime. Following this research process, it became clear that climate change established as a transformative stressor for planning in SEQ from 2005 onwards. Several factors contributed to this, including the devastation of the city of New Orleans caused by Hurricane Katrina in 2005; the widespread awareness-raising of Al Gore's An Inconvenient Truth documentary; the publication of the Stern Review in 2006, the IPCC Fourth Assessment Report in 2007 and the Garnaut Review in 2008 collectively created a significant level of institutional and public awareness of climate change as an issue for SEQ. Additionally, the near decade-long drought experienced in SEQ, along with major flooding events in rural Queensland of 2008, 2009 and 2010 created significant social stress, which in turn added to this emerging awareness of climate change as a significant nascent challenge.

The timeframe examined in this paper corresponds to the establishment and evolution of statutory regional planning in SEQ. This began with the development of the Southeast Queensland Regional Plan 2005-2026 (SEQRP 2005). The SEQRP 2009 replaced the Southeast Queensland Regional Plan 2005-2026 (SEQRP 2005). The 2005 plan was the first to have statutory force and was the result of over 15 years of policy development designed to manage regional pressures through statutory regional planning. All planning activities, regulations, strategies and interventions implemented by the 11 local councils in SEQ since 
2005 must correspond with the spatial objectives expressed in the SEQ Regional Plan (DIP 2009a, DlGPSR 2005). This gives the SEQ metro-regional planning regime significant institutional importance and establishes its responsibility for providing governance frameworks to 'manage regional growth and change in the most sustainable way to protect and enhance quality of life in the region' (DIP, 2009a, p. 4). The Southeast Queensland Regional Plan 2009-2031 (SEQRP 2009) replaced the SEQRP 2005. The SEQRP 2009 has a supplementary climate change plan, the Draft Southeast Queensland Climate Change Management Plan 2009-2031 (DSEQCCMP 2009), which addresses both climate change mitigation and adaptation. It is still awaiting statutory enactment at the time of writing (2012). The DSEQCCMP 2009 states that planning in SEQ has 'a key role' in building resilience to climate change impacts on human settlements across the region (DIP $2009 \mathrm{~b}$, p. 4). The current and past SEQ regional plans detail the institutional preferences of the SEQ metro-regional planning regime towards major planning issues since 2005, including climate change and climate adaptation.

Policies and objectives in the Southeast Queensland Regional Plan 20052026 demonstrated some institutional acknowledgement of climate change. Part F08 of the plan focused on urban development. Policies in that section did not directly nominate climate change as a planning issue but the focus of some policies did indicate a degree of institutional awareness of climate change. However, institutional responses were directed towards climate change mitigation rather than adaptation. Policies 8.2.1, 8.2.3, 8.2.4, 8.2.5, 8.7.3, 8.7.4 and 8.7.6 demonstrated institutional preferences for densification, urban consolidation, transit orientated development and the promotion of regional activity centres in order to decentralise employment, and in turn minimise car dependence and energy demand (DLGPSR 2005, pp. 65-75). Policy 8.2.1 emphasised that all new development should incorporate sub-tropical design principles to reduce energy consumption (DLGPSR 2005, p. 67). Overall, Part F08 of the SEQRP 2005 demonstrated that climate change mitigation was an institutional concern for the SEQ metro-regional planning regime in the mid 2000s, but that climate adaptation was not. I argue that this can be explained by the fact that the SEQRP 2005 was prepared during 2003/4, at a time when climate change had not yet manifested as a transformative stressor in SEQ. The severe drought in SEQ that lasted until 2010 was still at an early stage and major flood events did not frequently occur until later in the decade. As such, trigger events were limited when the SEQRP 2005 was being drafted. I argue that because climate change had not yet established itself as a transformative stressor, the implementation of rules of governance designed to operationalise climate change adaptation through planning would have appeared unnecessary to institutional actors at that time.

The SEQRP 2005 was replaced in 2009 with the current regional plan, the Southeast Queensland Regional Plan 2009-2031 (SEQRP 2009). The SEQRP 2009 is accompanied by the Draft Southeast Queensland Climate Change Management Plan 2009 (DSEQCCMP 2009). The SEQRP 2009 and DSEQCCMP 2009 demonstrate some institutional recognition of climate change as a transformative stressor. This suggests that both wider and region-specific trigger events were institutionally recognised during the lifetime of the SEQRP 2005 and that institutional actors considered some degree of response necessary when preparing the SEQRP 2009 
and DSEQCCMP 2009. Triggers included Hurricane Katrina, the publication of high-profile climate change reports by Stern (2006), IPCC (2007) and Garnaut (2008), as well as the Queensland drought that ran from 2003 to 2009/10 and the severe flooding in rural Queensland in 2008 and 2009. The growing institutional awareness of the emerging transformative effects of climate change is explicitly demonstrated in the minutes of Meeting 60 of the Regional Coordination Committee (RCC) in 2007. The RCC is the principal group responsible for directing and reviewing regional planning priorities in SEQ and as such, strongly influences institutional direction. During Meeting 60, when the SEQRP 2005 was being reviewed with regard to updating its content, the Office of Urban Management (OUM), the group responsible for writing the SEQRP 2005, stated that climate change needed urgent attention through planning in SEQ (Regional Coordination Committee 2007a). Their views were endorsed by various RCC members at the same meeting, including the then Queensland Minister for Sustainability, Climate Change and Innovation, the Honourable Andrew McNamara MP. Meeting 61 of the RCC also demonstrated nascent institutional awareness, with the RCC resolving to include climate change as an urgent area for review in respect of developing new regional plans. The RCC also endorsed terms of reference for developing improved climate change strategies through regional planning in SEQ at Meeting 61 (Regional Coordination Committee 2007b).

These developments indicate that climate change was beginning to be understood as a transformative stressor in SEQ from 2005 onwards. This, in turn, prompted incremental institutional change within the SEQ metro-regional planning regime. Subsequent institutional responses were enunciated through policies in both the SEQRP 2009 and the DSEQCCMP 2009. For example, Policies 1.3.1 - 1.3.6 of the SEQRP 2009 expressed institutional preferences for reducing greenhouse gas emissions, improving energy efficiency, promoting carbon storage and increasing the take-up of renewable energy technologies (DIP 2009a, p. 42). The DSEQCCMP 2009 reiterated these policies and outlined a set of 'climate change aspirations for SEQ' including increased provision of public transport, more compact urban form, potable water management and a move towards more localised food provision (DIP 2009b, p. 13-14). The general climate change policies in the SEQRP 2009 and the DSEQCCMP 2009 did not significantly advance those seen in the SEQRP 2005, suggesting that institutional preferences remained primarily focused on climate change mitigation. However, the SEQRP 2009 and DSEQCCMP 2009 both departed from the earlier regional plan by addressing climate adaptation to a limited extent.

The institutional elaboration of climate adaptation through policies and objectives in the SEQRP 2009 and DSEQCCMP 2009 was narrow, but nonetheless present, during the timeframe examined in this paper. For example, the SEQRP 2009 stated that planning processes in SEQ can reduce risks from projected climate change effects by avoiding development in hazardous areas, improving the design of developments and infrastructure and improving community preparedness. Policies 1.4.1 - 1.4.3 also expressed these broad aims and called for the adaptation strategies to minimise vulnerability to riverine flooding, sea level rise, storm surges, heatwaves and other severe weather events wrought by climate change (DIP 2009a, p. 44). The DSEQCCMP 2009 also outlined the necessity of 
climate adaptation in SEQ and proposed thirteen draft actions to increase adaptive capacity across the region (DIP 2009b, p. 14, 30-35). Four were acknowledged by the plan as being underway in 2009. These included preparing a new coastal plan (Draft Action 20); implementing the policies of the coastal plan across the region (Draft Action 22); acquiring digital elevation data for coastal areas (Draft Action 23) and developing a regional summary of projected climate change impacts for SEQ (Draft Action 27). Applied to the transformative stressors framework, these developments suggest that incremental institutional change did occur within the SEQ metro-regional planning regime, resulting in the operationalisation of climate adaptation becoming part of urban and regional planning governance. However, the question remains as to whether this incremental change is sufficient to respond to climate change as a transformative stressor by operationalising climate adaptation as a central principal of metro-regional planning governance. I argue that the evidence suggests that the level of institutional change was not extensive enough. Despite the advances made by its inclusion in the relevant plans, the institutional elaboration of climate adaptation as a central issue for planning and thus urban governance in SEQ was generally weak.

Whilst the climate change adaptation policies and regulations espoused by the SEQ metro-regional planning regime up to 2010 were limited, they at least acknowledged an institutional recognition of the need for climate adaptation to be part of governance structures in SEQ to 2010 and beyond. The fact that climate adaptation now features in the regional planning framework indicates that incremental institutional change took place in the SEQ metro-regional planning regime since climate change became a transformative stressor in 2005. This is positive, even if the extent of change is limited. I make the following observations when applying these developments to the transformative stressors model. First, trigger events, which occurred during the lifetime of the SEQRP 2005, seem to have focused institutional attention on climate change as a transformative stressor. Second, these triggers opened windows of opportunity for institutional change and were exploited to a limited degree. This suggests that institutional actors must have expressed preferences for change at the time. Third, institutional capacity was sufficient to allow change but the extent of institutional change with respect to the operationalisation of climate adaptation was incremental rather than episodic. Finally, irrespective of institutional change having occurred up to 2010, there remains a lack of specific guidance addressing how local councils in SEQ can deliver climate adaptation through planning processes. The policies and objectives related to climate adaptation in the regional planning framework were, and indeed remain, insufficiently prescriptive and so lack the capacity to properly orientate local planning activities towards climate adaptation. This, I argue, is because climate adaptation was just one institutional concern amongst many from 2004 to 2010. While climate change began to exert as a transformative stressor from 2005 onwards and generated some institutional responses, these were not sufficiently operationalised to ensure that climate adaptation became a central tenet of planning governance in SEQ.

The SEQRP 2009 continues to function as the primary planning document in SEQ. Its policies and objectives in respect of climate change and climate adaptation, along with the DSEQCCMP 2009, remain in place at the present time 
(2012). Institutional responses to climate change as a transformative stressor in SEQ consequently remain the same as those discussed in this paper. In spite of the limited institutional expression of climate adaptation as part of a comprehensive response to climate change as a transformative stressor, there remains scope for improved responses through planning governance in SEQ. The consequences of the major flooding in SEQ in early 2011 may yet come to represent a set of triggers strong enough to prompt more substantial institutional change within the SEQ metro-regional planning regime. That could ultimately compel a fuller operationalisation of climate adaptation as a central tenet of metro-regional planning governance. The SEQ planning regime has demonstrated a capacity for incremental change in respect of climate adaptation, but I argue that episodic change is needed if climate adaptation is to be fully operationalised through planning governance. Increased incidences and severity of flooding are part of the predicted impacts of climate change in SEQ. In this regard, the floods of 2011 offer a vivid example of one type of transformative stress that climate change may bring to bear on SEQ through similar events over the coming decades. Loss of life, livelihoods and assets were experienced across the region in 2011. Impacts were especially heavy in urban areas, most notably in Brisbane and Toowoomba. These may yet prove to be the triggers that will compel episodic institutional change within the SEQ metro-regional planning regime. I submit that the social stresses created by the 2011 floods and other future events have the capacity to ensure that institutional actors will find it difficult to resist significant institutional change over time. However, the question of whether episodic institutional change in respect of climate adaptation actually follows remains unresolved for now.

As a final consideration, it must be acknowledged that institutional change, especially episodic change, is often conditioned and influenced by the preferences of political and government actors. Whether politicians and government officials in SEQ recognise climate change as a transformative stressor and understand the necessity of operationalising climate adaptation through planning governance frameworks remains an unresolved question. I argue that the existing focus on climate adaptation in the SEQRP 2009 and DSEQCCMP 2009 offers some hope for more significant institutional expression in the future. These plans were the products of a Labour state government and indicate awareness within that party of climate change as a transformative stressor requiring responses from institutional governance frameworks. There will be a state election in Queensland in March 2012, and should Labour lose office, it appears that the Liberal National Party (LNP) will support an agenda of climate adaptation. Current LNP policy on climate adaptation illustrates the party's support for research into adaptation strategies, as well as support for the Commonwealth Scientific and Industrial Research Organisation's (CSIRO) Adaptation Flagship (LNP 2010). Additionally, the impacts of the 2011 SEQ floods forced politicians and officials to publicly confront the devastating impacts of extreme weather events. Political management and strategy making in respect of this event remains under significant media and public scrutiny in SEQ, suggesting that the political sphere would be unwise ignore these issues in the future.

\section{Conclusion}


Social science characterises institutions as social entities that structure and coordinate social interactions across a number of settings. This is achieved through the imposition of rules of governance, which can take the form of policies, regulations, laws and conventions, amongst others. Institutions can undergo institutional change when faced with trigger events and associated stressors that require new rules of governance to better manage their impact. This paper offered a new conceptual framework that proposed a typology of stressors referred to as 'transformative stressors.' These are characterised by their capacity to compel institutional change even in situations where resistance from institutional actors is present, or where institutional capacity may be limited. Climate change was identified as one example of a transformative stressor. This paper has argued that the improved operationalisation of climate adaptation should be a central tenet of a comprehensive planning response to the transformative stresses of climate change and its effects. The role of planning regimes as social institutions responsible for establishing and maintaining governance frameworks was examined in this context, along with the capacity of planning regimes to respond to climate change as a transformative stressor.

This paper argued that climate change began to assert itself as a transformative stressor in Southeast Queensland (SEQ) from 2005 onwards. The SEQ metro-regional planning regime is a key institution charged with implementing governance frameworks to guide development activities across the metropolitan region. As such, this paper argued that responding to climate change as a transformative stressor, particularly through the operationalisation of climate adaptation, is a vital institutional challenge. This paper argued that the current and past SEQ regional plans and institutional processes document the institutional preferences of the SEQ metro-regional planning regime towards many planning issues from 2004-2010, including climate change and climate adaptation. It was argued that operationalising climate adaptation through institutional change is central in responding to climate change as a transformative stressor in SEQ. The analysis of SEQ statutory regional plans shows that the SEQ metro-regional planning regime underwent incremental, though not episodic, institutional change in response to transformative stresses related to climate change between 2004 and 2010. It was argued that the inclusion of policies and objectives relating to climate change adaptation in the Southeast Queensland Regional Plan 2009-2031 and Draft Southeast Queensland Climate Change Management 2009-2031 showed increasing institutional awareness of climate change as a transformative stressor and represented incremental institutional change. It was also argued that episodic institutional change in response to climate change as a transformative stressor might occur in the future, particularly in respect of the social stresses like those created by the 2011 floods in SEQ. The widespread, costly and damaging impacts of these events could yet prove to be triggers for episodic institutional change within the SEQ metro-regional planning regime. Episodic change in this context would ably demonstrate the nature and character of climate change as a transformative stressor that demands institutional responses through planning governance focused on climate adaptation in SEQ. In this regard, the experiences of the SEQ metro-regional planning regime can provide valuable insights for 
scholars and practitioners seeking to better understand institutional responses to climate change as a transformative stressor.

\section{Acknowledgements}

The author wishes to thank Jago Dodson for his helpful comments on earlier drafts of this paper.

\section{References}

Alden, J. Albrechts, L. and da Rosa Pires, A. 2001. In Search of New Approaches for Planning. In: Albrechts, L., Alden, J. and da Rosa Pires, A., eds. The Changing Institutional Landscape of Planning. Aldershot: Ashgate, pp. 1-7.

Alexander, E. R. 2005. Institutional Transformation and Planning: From Institutionalization Theory to Institutional Design. Planning Theory, Vol. 4, No. 3: 209-222.

Alston, L. 1996. Empirical Work in Institutional Economics: An Overview. In: Alston, L., Eggertsson, T. and North, D., eds. Empirical Studies in Institutional Change. Cambridge: Cambridge University Press, pp. 25-30.

Condon, P. M., Cavens, D. and Miller, N. (2009) Urban Planning Tools for Climate Change. Cambridge: Lincoln Institute of Land Policy.

Connor, R. D. and Dovers, S. R. 2002. Institutional Change and Learning for Sustainable Development - Working Paper 2002/1. Canberra: Centre for Resource and Environmental Studies, ANU.

Connor, R. D. and Dovers, S. R. 2004. Institutional Change for Sustainable Development. Cheltenham: Edward Elgar.

Cortell, A. P. And Peterson, S. 1999. Altered States: Explaining Domestic Institutional Change. British Journal of Political Science, Vol. 29, pp. 177-203.

David, P. 1985. Clio and the Economics of QWERTY. American Economic Review, Vol. 75, pp. 332-337.

[DLGPSR] Department of Local Government, Planning, Sport and Recreation. 2005. South East Queensland Regional Plan 2005-2026. Brisbane: Queensland Government.

[DIP] Department of Infrastructure and Planning. 2009a. South East Queensland Regional Plan 2009-2031. Brisbane: Queensland Government.

[DIP] Department of Infrastructure and Planning. 2009b. Draft South East Queensland Climate Change Management Plan 2009-2031. Brisbane: Queensland Government.

Dovers, S. and Hezri, A. 2010. Institutions and policy processes: the means to the ends of adaptation. Wiley Interdisciplinary Reviews: Climate Change, Vol. 1, pp. 212-231.

Faludi, A. 2000. The Performance of Spatial Planning. Planning Practice and Research, Vol. 15, No. 4, pp. 299-318.

Forester, J. 1989. Planning in the Face of Power. California: University of California Press.

Fünfgeld, H. 2010. Institutional Challenges to Climate Risk Management in Cities. Current Opinion in Environmental Sustainability, Vol 2: 156-160.

Garnaut, R. 2008. Garnaut Climate Change Review: Report to the Commonwealth, State and Territory Governments of Australia. Port Melbourne: Cambridge 
University Press.

Gleeson, B. 2008. Waking from the Dream: An Australian Perspective on Urban Resilience. Urban Studies, Vol. 45, pp. 2653-2668.

Hajer, M. 1993 Discourse Coalitions and the Institutionalisation of Practice: The Case of Acid Rain in Great Britain. In: Fischer, F. and Forester, J. eds. The Argumentative Turn in Policy Analysis and Planning. London: Routledge.

Hajer, M. 1995. The Politics of Environmental Discourse, Environmental Modernisation and the Policy Process. Oxford: Clarendon Press.

Healey, P. et al 1999. European Developments in Strategic Spatial Planning. European Planning Studies, Vol. 7, No. 3, pp. 339-355.

Hennessy, K., et al. 2007. Australia and New Zealand. In: Parry et al., eds. Climate Change 2007: Impacts, Adaptation and Vulnerability. Contribution of Working Group II to the Fourth Assessment Report of the Intergovernmental Panel on Climate Change. Cambridge: University Press.

Hogan, J. 2006. Remoulding the Critical Junctures Approach. Canadian Journal of Political Science, Vol. 39, pp. 657-679.

IPCC 2007. Summary for Policymakers. In: Parry, M.L., et al, eds. Climate Change 2007: Impacts, Adaptation and Vulnerability. Contribution of Working Group II to the Fourth Assessment Report of the Intergovernmental Panel on Climate Change. Cambridge: Cambridge University Press.

Kingston, C. and Caballero, G. 2009. Comparing theories of institutional change. Journal of Institutional Economics, Vol. 5, pp. 151-180.

Krasner, S. D. 1984 Approaches to the State: Alternative Conceptions of Historical Dynamics. Comparative Politics, Vol. 16, pp. 223-244.

Liebcap, G.D. 1989. Contracting for Property Rights. Cambridge: Cambridge University Press.

[LNP] Liberal National Party. 2010. Direct Action Plan on the Environment and Climate Change. Barton: Liberal National Party. Available from: http://liberal.org.au/ /media/Files/Policies\%20and\%20Media/Environment/ The\%20Coalitions\%20Direct\%20Action\%20Plan\%20Policy.ashx Accessed September 10 2011.

Low, N. and Astle, R. 2009. Path Dependence in Urban Transport: An Institutional Analysis of Urban Passenger Transport in Melbourne, Australia, 1956-2006. Transport Policy, Vol. 16, pp. 47-58

Major Cities Unit. 2010. State of Australian Cities 2010. Canberra: Major Cities Unit, Infrastructure Australia.

March, J. and Olsen, J. 1994. Institutional Perspectives on Political Institutions. Governance, Vol. 9, pp. 247-264.

Matthews, T. 2011. Climate Change Adaptation in Urban Systems: Strategies for Planning Regimes. Brisbane: Urban Research Program, Griffith University.

Matthews, T. 2011. Operationalising Climate Adaptation through Institutional Change: Conceptual an Empirical Insights. Proceedings of the $3^{\text {rd }}$ World Planning Schools Congress, Perth, 4-8 July 2011.

McFaul, M. 1995. State Power, Institutional Change and the Politics of Privatisation in Russia. Word Politics, Vol. 47, pp. 210-243.

Measham, T. G., Preston, B. L., Smith, T. F., Brooke, C., Goddard, R. Withycombe, G. and Morrison, C. 2011. Adapting to Climate Change through Municipal Planning: 
Barriers and Challenges. Mitigation and Adaptation Strategies for Global Change, Vol. 14 (3), pp. 251-283.

Moser, S. C. and Ekstrom, J. A. 2010. A Framework to Diagnose Barriers to Climate Change Adaptation. Proceedings of the National Academy of Sciences of the United States of America, 107(51), pp. 22026-22031.

Newman, P., T. Beatley, Boyer, H. 2009. Resilient Cities: Responding to Peak Oil and Climate Change. London: Island Press.

North, D. C. 1990. Institutions, Institutional Change and Economic Performance. Cambridge: Cambridge University Press.

North, D. C. 1993. Five Propositions about Institutional Change. In: Knight, J. and Sened, I. eds. Explaining Social Institutions. Ann Arbor: University of Michigan Press.

Olson, M. 1982. The Rise and Decline of Nations. New Haven: Yale University Press.

Ostrom, E. 2005. Understanding Institutional Diversity. New Jersey: Princeton University Press.

Peters, G. 2005. Institutional Theory in Political Science: The New Institutionalism. New York: London and Pinter.

Regional Coordination Committee. 2007a. Minutes of RCC Meeting 60. Brisbane: Regional Coordination Committee.

Regional Coordination Committee. 2007b. Minutes of RCC Meeting 61. Brisbane: Regional Coordination Committee.

Ruth, M. and Coelho, D. 2007. Understanding and Managing the Complexity of Urban Systems under Climate Change. Climate Policy, Vol. 7, pp. 317-336.

Schmidt, V.A. 2010. Taking Ideas and Discourse Seriously: Explaining Change through Discursive Institutionalism as the Fourth 'New Institutionalism'. European Political Science Review, Vol. 2(1), pp. 1-25.

Smith, I., Dodson, J., Gleeson, B. and Burton, P. 2010. Growing Adaptively: Responding to climate change through regional spatial planning in England and Australia. Brisbane: Urban Research Program, Griffith University.

Stern, N. 2006. Stern Review on The Economics of Climate Change. London: HM Treasury.

[UN] United Nations. 2009. State of the World Population 2009. New York: UNFPA.

Wilson, E. 2006. Adapting to Climate Change at the Local Level: The Spatial Planning Response. Local Environment, Vol. 11(6), pp. 609-625.

Wilson, E. and Piper, J. 2010. Spatial Planning and Climate Change. London: Routledge.

Young, O. R. 1999. Governance in World Affairs. Ithaca: Cornell University Press.

Young, O. R. 2002. The Institutional Dimensions of Environmental Change: Fit, Interplay and Scale. Cambridge: MIT Press.

Young, O. R. 2010. Institutional Dynamics: Resilience, Vulnerability and Adaptation in Environmental and Resource Regimes. Global Environmental Change, Vol. 20, pp. 378-385. 
